\title{
Response Surface Optimization of Phenolic Compounds Extraction From Steam Exploded Oak Wood (Quercus mongolica) ${ }^{1}$
}

\author{
Ji Young Jung ${ }^{2} \cdot \mathrm{Si}$ Young $\mathrm{Ha}^{2} \cdot$ Jae-Kyung Yang ${ }^{2, \dagger}$
}

\begin{abstract}
Steam explosion was applied to extract phenolic compounds from oak wood (Quercus mongolica). The effects of three independent factors (ethanol concentration, extraction temperature and extraction time) on the total phenolic content, DPPH radical scavenging activity, and antimicrobial activity from the steam exploded oak wood were optimized using response surface methodology (RSM). The independent variables were coded at three levels and their actual values were selected on the basis of preliminary experimental results. The following optimal extraction conditions were selected: ethanol concentration $82.0 \%$, extraction temperature $71.7^{\circ} \mathrm{C}$, and extraction time $60.5 \mathrm{~min}$ for total phenolic content; ethanol concentration $78.3 \%$, extraction temperature $70.3{ }^{\circ} \mathrm{C}$, and extraction time $57.6 \mathrm{~min}$ for DPPH radical scavenging activity; ethanol concentration $80.6 \%$, extraction temperature $68.4^{\circ} \mathrm{C}$, and extraction time $59.0 \mathrm{~min}$ for antimicrobial activity. The experimental values agreed with those were predicted within confidence intervals indicating the suitability of RSM in optimizing the ethanol extraction of phenolic compounds from the steam exploded oak wood. Under the optimized conditions, the experimental value of the total phenolic content was $111.8 \mathrm{mg}$ GAE/g dry steam exploded oak wood, DPPH free radical scavenging activity was $65.7 \%$, and antimicrobial activity was $17.0 \mathrm{~mm}$, and those are reasonably close to the predicted values $(109.2 \mathrm{mg} \mathrm{GAE} / \mathrm{g}$ dry steam exploded oak wood, $62.3 \%$ and $15.9 \mathrm{~mm}$, respectively).
\end{abstract}

Keywords : oak wood, steam explosion, ethanol extraction, phenolic compound, response surface methodology

\section{INTRODUCTION}

Natural phenolic compounds obtained from plants are well recognized for their antioxidant activities. These compounds show various physiological and pharmacological properties such as molluscicidal, anthelmintic, and antihepatoxic activities. The use of natural products such as phenols as antifungal drugs is of great importance. Many natural phenolic compounds extracted from natural plants have been reported to have antifungal activities. Some examples of such phenolic compounds are flavonoids, phenolic acids, stilbenes, tocopherols, tocotrienols, ascorbic acid and carotenoids (Zhao et al., 2014). Natural phenolic compounds are being

1 Date Received August 24, 2017, Date Accepted October 30, 2017

2 Division of Environmental Forest Science and Institute of Agriculture \& Life Science, Gyeongsang National University, Jinju 52828, Republic of Korea

† Corresponding author: Jae-Kyung Yang (e-mail: jkyang@gnu.ac.kr, ORCID: 0000-0003-0423-6398) 
extensively researched in recent years due to the increasing limitations on the use of synthetic antioxidants (such as butylated hydroxytoluene, butylated hydroxyanisole and tertiary butylhydroquinone) and increased public concern on health issues. In addition, research is also being conducted to identify novel antioxidants from natural sources such as low-cost agricultural, forest, or industrial wastes (Meullemiestre et al., 2016; Wang et al., 2015; Wong et al., 2015; Fu et al., 2014; Salem et al., 2014).

Quercus trees, commonly known as oaks, that forest comprise $64 \%$ of the total land area in Korea, and tree species in the genus Quercus are dominant covering about $27 \%$ of total forested area (Sim and Han, 2003). Oaks are a rich source of saponins and polyphenols, particularly tannins, flavonoids, and proanthocyanidins and important potential source of natural antioxidants. Acorns, the fruit of oak trees, have long been employed as a source of boar feed, tannin, oil, and especially food because of the high content of carbohydrates, amino acids, proteins, lipids, and various sterols (Lopes and Bernardo-Gil, 2005; Cantos et al., 2003). Oak bark is known to accumulate large amounts of polyphenols and these compounds are mainly defined as ellagitannins and condensed tannins. So, bark of some oak has been used in medicine (Panchal and Brown, 2013). Oak heartwood shows high levels of ellagitannins, hydroxybenzoic and hydroxycinnamic acids and aldehydes, and volatile compounds that can vary greatly depending on the species and geo- graphical origin of the wood as well as the processing it undergoes in cooperage. The most abundant polyphenols are the monomer ellagitannins, castalagin, roburin $\mathrm{E}$, vescalagin, and grandinin, and low molecular weight phenolic compounds such as ellagic and gallic acids, besides lignin constituents, especially vanillin (Sanz et al., 2010).

Generally, oak heartwood is used for oak barrels for wine aging and oak barrels is toasting or seasoning. Several studies have described changes in the composition of oak as it is toasted (Chatonnet, 1992; Cutzach et al., 1997). The process of barrel toasting probably has the main influence on the chemical compounds of the oak such as hemicellulose, cellulose and lignin. A toasting is carried out to help a superficial degradation of oak that produces new aromatic compounds, which are susceptible to migrate into wine or spirits during their aging, affecting their organoleptic properties (Chatonnet, 1992). The type of heat treatment, toasting was the process that most influenced the phenolic composition of wood on medium intensity condition $\left(160-170^{\circ} \mathrm{C}, 35 \mathrm{~min}\right)$ (Cadahía et al., 2001). Also, it was also observed that phenolic compound quality and quantity are narrowly related to toasting intensity. At the beginning of heat treatment, there is a breakdown of cellulose that acts as the initiating stage in the degradation of lignin. The breaking of hydrogen and covalent bonds between cellulose and lignin destroys the cohesion of the lignocellulose network and facilitates the depolymerization by means of the rearrangement of the terminal 
units of lignin. The formation of cinnamic aldehydes can be a result of the breaking of aryl ether bonds ( $\alpha-\mathrm{O}-4$ and $\beta-\mathrm{O}-4)$, which are less stable than C-C bonds (Sarni et al., 1990).

Recently, among heat treatment methods, which do not require the addition of chemicals and short treatment time, steam explosion has been widely applied to lignocellulosic biomass. The steam explosion has been attractive for the degradation and separation of not only structural components, i.e. cellulose, hemicellulose, and lignin, but also antineoplastic constituents from plant biomass. The principle of steam explosion treatment is the steam hydrolysis at high temperature and pressure, followed by sudden reduction of the pressure for physical treatment of the hydrolyzed product to produce low-molecular weight substances. The lignin is broken down into low-molecular-weight products $\left(M_{\mathrm{r}} 400-8000\right)$ which retain the basic lignin structure and are moderately reactive. Since the lignin has been extensively depolymerized by cleavage of the $\beta$-aryl-ether bonds, it is soluble in alkaline solutions or certain organic solvents. Also the hemicellulose is partially broken down and is predominantly soluble in water.

The qualitative and quantitative studies of bioactive compounds such as lignin-derived or sugar-derived compound from plant materials mostly rely on the selection of proper extraction method (Sasidharan et al., 2011). There are several methods established for the extraction of phenolic compound from plant materials. Those methods vary in solvents and conditions used.
The extraction method is essential for the accurate quantification of antioxidant content and capacity.

Solvent extraction is frequently used for isolation of antioxidant and extraction yield is dependent on the solvent and method of extraction, due to the different antioxidant potentials of compounds with different polarity. Many factors such as solvent composition, extraction time, extraction temperature (Wettasinghe and Shahidi, 1999), solvent to solid ratio (Cacace and Mazza, 2003) and extraction pressure (Cacace and Mazza, 2002), among others, may significantly influence on the extraction efficacy.

Several extraction techniques have been reported for extraction of phenolic compounds from different matrices using solvents with different polarities, such as ethanol, methanol, water, ethyl acetate and petroleum ether (Cheung et al., 2003). Type of solvent has been the most investigated factor. Alcoholic solvents have been commonly employed to extract phenolics from natural sources: they give quite high yield of total extract even though they are not highly selective for phenolic compound. Particularly, mixtures of alcohols and water have revealed to be more efficient in extracting phenolic constituents than the corresponding mono-component solvent system (Yilmaz and Toledo, 2006; Pinelo et al., 2005). Since the use of ethanol (a dietary alcohol) may be preferable than methanol in view of a food application of the extracts, in the present paper the effect of ethanol concentration on phenolic compound extraction from steam exploded oak was 
investigated.

Extraction time and temperature are important parameters to be optimized even in order to minimize energy cost of the process. Many authors agree in the fact that an increase in the working temperature favors extraction enhancing both the solubility of solute and the diffusion coefficient, but also that beyond a certain value phenolic compounds can be denatured (Spigno and De Faveri, 2007; Pinelo et al., 2005; Yilmaz and Toledo, 2006).

Response surface methodology (RSM) is an effective optimization tool for investigating many factors and their interactions influencing the response with fewer experimental trials. Accordingly, RSM has been increasingly utilized to optimize extraction conditions for antioxidative phenolic compounds over the past few years (Belwal et al., 2016; Sa'adi et al., 2014). However, little researches have been done on the optimization of phenolic compound extraction from steam exploded source by response surface methodology (RSM).

We investigated phenolic compounds of steam exploded treated Quercus mongolica, as well as their antioxidant activity using steam explosion condition. Therefore, the aim of this work was to analyze the influence of ethanol extraction conditions on the total phenolic content, antioxidant capacity and antimicrobial activity of steam exploded oak wood using an experimental design and the response surface methodology. The parameters to be optimized were temperature and time, both related with the minimization of the energy cost of the proc- ess and solvent concentration.

\section{MATERIALS and METHODS}

\subsection{Material}

Oak wood (Quercus mongolica) was supplied by a Korea Forest Research Institute. The dimensions of the oak wood chips were smaller than $30 \times 50 \times 30 \mathrm{~mm}$, while dusts (particles < $1 \mathrm{~mm}$ ) were removed before steam explosion. An external dryer was used to dry the chips to below $15 \%$ before steam explosion.

\subsection{Steam Explosion}

The "severity factor: $\log (R o)$ " is used to map the destruction, desegregation, and depolymerization of oak wood. Ro is calculated using the following relation, Eq. (1) (Heitz et al, 1987):

$$
R o=\{t \times \exp [(T-100) / 14.75]\} \cdots \cdots \cdots \cdot \ldots \text { Eq. }(1)
$$

where $T$ is the temperature $\left({ }^{\circ} \mathrm{C}\right)$ and $t$ the time (min). A steam temperature of $160-240^{\circ} \mathrm{C}$ and treatment time of 5 - $15 \mathrm{~min}$ were applied to realize a $\log (R o)=2.5,3.1,3.4,3.5,3.6,3.9$, 4.1, 4.2, 4.5, 4.7 and 5.3 (Table 1). The steam exploded oak wood was recovered in a cyclone and after cooling to about $40^{\circ} \mathrm{C}$ filtered for liquid and solid fraction.

\subsection{Extraction procedure of steam exploded oak wood}

Extractions of steam exploded oak wood 
Response Surface Optimization of Phenolic Compounds Extraction From Steam Exploded Oak Wood (Quercus mongolica)

Table 1. Steam explosion conditions, calculated severity factor and yield of ethanol extract

\begin{tabular}{cccc}
\hline Sample & Temperature $\left({ }^{\circ} \mathrm{C}\right)$ & Time $(\mathrm{min})$ & ${\text { Severity factor }(R \mathrm{o})^{\mathrm{a}}}^{\mathrm{a}}$ \\
\hline \hline 1 & 160 & 5 & 2.5 \\
2 & 180 & 5 & 3.1 \\
3 & 180 & 10 & 3.4 \\
4 & 180 & 15 & 3.5 \\
5 & 200 & 5 & 3.6 \\
6 & 200 & 10 & 3.9 \\
7 & 200 & 15 & 4.1 \\
8 & 220 & 5 & 4.2 \\
9 & 220 & 10 & 4.5 \\
10 & 220 & 15 & 4.7 \\
11 & 240 & 15 & 5.3 \\
\hline${ }^{a}$ Severity factor $(R \mathrm{o})=\{t \times \exp [(T-100) / 14.75]\} . T$ is the temperature $\left({ }^{\circ} \mathrm{C}\right)$ and $\mathrm{t}$ is the duration of treatment $(\min )($ Overend and Chornet, \\
1987)
\end{tabular}

were done in glass bottles using ethanol as solvent. In general, $1 \mathrm{~g}$ of steam exploded oak wood was placed in glass bottle with $40 \mathrm{~m} \ell$ of solvent, and then placed in a shaking water bath at a speed of $100 \mathrm{rpm}$. Upon completion of extraction, the extract was filtered through paper filter (Whatman No. 2). The filtrates were collected, placed in glass centrifuge tubes, and stored at $-4{ }^{\circ} \mathrm{C}$ until use. Each extraction was run in triplicate.

\subsection{Determination of total phenolic content}

The total phenolic content (TPC) was determined by Folin-Ciocalteu method according to the reported procedure ( $\mathrm{Li}$ et al., 2008). Briefly, a extracts $(1 \mathrm{~m} \ell)$ with proper dilution were mixed with $1 \mathrm{~m} \ell$ of Folin-Ciocalteu reagent (10 times dilution) and allowed to react for $3 \mathrm{~min}$ at $30^{\circ} \mathrm{C}$ in the dark. Then $0.8 \mathrm{~m} \ell$ of saturated $\mathrm{Na}_{2} \mathrm{CO}_{3}$ solution was added and al- lowed the mixture to stand for $1 \mathrm{~h}$. The absorbance of the reaction mixture at $765 \mathrm{~nm}$ was measured by using UV- spectrophotometer (HITACHI U-3000, Tokyo, Japan). A calibration curve of gallic acid was prepared, and the TPC was standardized against gallic acid and expressed as mg GAE acid equivalent per gram of dry steam exploded wood.

\subsection{Determination of DPPH free radical scavenging activity}

DPPH radical scavenging activity (DPPH) were calculated based on the change of absorbance due to the decrease in 2,2-diphenyl-1-picrylhydrazyl in relation to the control value (Ghasemi et al., 2009). Considering the color of extract, the ethanol solution $(1 \mathrm{~m} \ell)$ instead of $0.5 \mathrm{mM}$ DPPH in ethanol $(1 \mathrm{~m} \ell)$ was used as a color blank. As a control water or ethanol $(1 \mathrm{~m} \ell)$ was added instead of the extract. 
Table 2. The Box-Behnken design for the RSM



Briefly, a $0.1 \mathrm{mM}$ of ethanolic DPPH solution was prepared. The initial absorbance of the DPPH in ethanol was measured at $517 \mathrm{~nm}$ and did not change throughout the period of assay. An aliquot $(0.1 \mathrm{~m} \ell)$ of each extract (with appropriate dilution if necessary) was mixed with $3.0 \mathrm{~m} \ell$ of ethanolic DPPH solution and incubated for $30 \mathrm{~min}$ at $30^{\circ} \mathrm{C}$ in dark. Then the absorbance at $517 \mathrm{~nm}$ was measured. The DPPH (\%) was calculated by the following equation:

DPPH $(\%)=\left(1-A_{\text {sample }} / A_{\text {control }}\right) \times 100 \cdot$ Eq. (2) where $A_{\text {sample }}$ is the absorbance in the presence of sample and $A_{\text {control }}$ is the absorbance in the absence of sample, respectively.

\subsection{Determination of antimicrobial activity}

The disc diffusion method was used to the antimicrobial activity. In vitro antimicrobial activity was screened by using MRS agar (1.0\% peptone, $1.0 \%$ beef extract, $0.4 \%$ yeast extract, $2.0 \%$ glucose, $0.5 \%$ sodium acetate trihydrate, $0.1 \%$ polysorbate 80 (also known as Tween 80 ), $0.2 \%$ dipotassium hydrogen phosphate, $0.2 \%$ triammonium citrate, $0.02 \%$ magnesium 
sulfate heptahydrate, $0.005 \%$ manganese sulfate tetrahydrate, $1.0 \%$ agar). For antimicrobial activity determination and growth studies, $24 \mathrm{hrs}$ cultures (ranging from 1 to $5 \times 10^{8}$ colonyforming units $(\mathrm{CFU}) / \mathrm{m} \ell)$ of Staphylococcus aureus were used. The MRS agar plates were prepared by pouring $15 \mathrm{~m} \ell$ of molten media into sterile petri plates. The plates were allowed to solidify for $12 \mathrm{hrs}$ and $50 \mu \ell$ inoculum suspension was swabbed uniformly and the inoculum was allowed to dry for 5 minutes. The different of extracts $(30 \mu \ell /$ disc $)$ were loaded on $6 \mathrm{~mm}$ sterile disc. The loaded disc was placed on the surface of medium and the compound was allowed to diffuse for 5 minutes and the plates were kept for incubation at $37^{\circ} \mathrm{C}$ for 24 hrs. At the end of incubation, inhibition zones formed around the disc were measured with transparent ruler in millimeter. These studies were performed in triplicate.

\subsection{Experimental design of RSM}

The process conditions for ethanol extraction of total phenolic content from steam exploded oak wood were optimized by RSM. Response surface methodology (RSM) was used to optimize the extraction process to yield the highest amount of total phenolic content and DPPH by controlling the process variables: ethanol concentration $\left(70-90 \%, x_{1}\right)$, temperature $\left(60-80^{\circ} \mathrm{C}\right.$, $x_{2}$ ), time (30 - $\left.90 \mathrm{~min}, x_{3}\right)$. A Box-Behnken design was adopted to optimize the extraction conditions, as shown in Table 2. The 17 experiments were run in random order to minimize the effects of unexpected variability in observed responses due to extraneous factors. Response surfaces, as represented by Fig. 3 and Fig. 4 were drawn by using the RSREG (SAS: statistical analysis system, SAS institute U.S.A). The experimental data were fitted to a second order polynomial model (Eq. (3)) and the regression coefficients were obtained by multiple linear regression

$$
Y=\beta_{0}+\sum_{i=1}^{3} \beta_{i} X_{i}+\sum_{i=1}^{3} \beta_{i i} X_{i}^{2}+\sum_{\substack{i=1 \\ i<j}}^{2} \sum_{j=2}^{3} \beta_{i j} X_{i} X_{j} \quad \cdots \text { Eq. }
$$

where $\mathrm{Y}$ is the predicted response (total sugar, reducing sugar and antimicrobial activity); $\beta 0$, $\beta \mathrm{i}, \beta \mathrm{ii}$ and $\beta \mathrm{ij}$ are the regression coefficients for intercept, linear, quadratic and interaction terms, respectively; $X_{\mathbf{1}}$ and $X_{\mathbf{j}}$ are the independent variables $(i \neq j)$. Measurements were performed in duplicate and a Statistical Analysis System was used to fit the second-order polynomial equation to the experimental data.

\subsection{Statistical Analysis}

Obtained data were subjected to analysis of variance to determine the growing medium effects. Statistical analysis had been carried out with SAS statistical software and according to analyzing from ANOVA test and comparing data mean to Duncan test. Duncan's multiple comparison range test was used to determine significant differences between the means. 


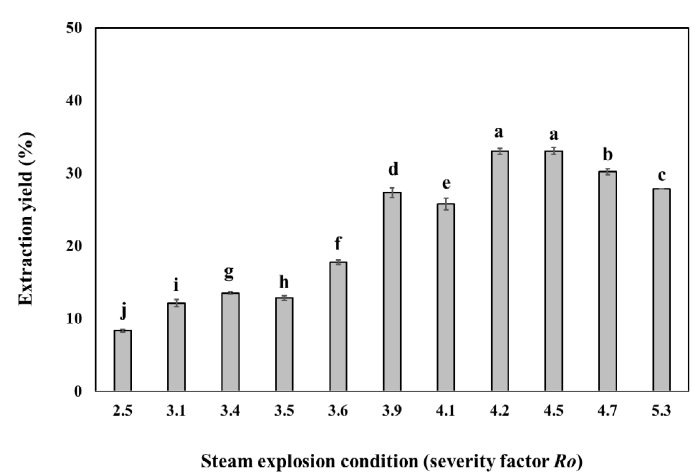

Fig. 1. Effect of steam explosion on extraction yield. The data are expressed as the mean $\pm \mathrm{SD}(n=3)$.

\section{RESULTS and DISCUSSION}

\subsection{Effect of Steam Explosion on Extraction Yield of Oak Wood}

Oak wood chips were steam-exploded at temperatures ranging from $160^{\circ} \mathrm{C}$ to $240^{\circ} \mathrm{C}$ and after various times in the interval of 5-15 $\mathrm{min}$. The severity factor $(R o)$, commonly used for the comparison of steam explosion treatments at different temperatures and times (Heitz et al., 1987), was calculated for each experiment (Table 1). After water washing and drying of the exploded material, the material was extracted with the ethanol solvent. The steam explosion treatment resulted in the extraction yield of $8.3-33.1 \%$ (Fig. 1). Most of the hemicellulose and lignin were modified becoming soluble in ethanol solvent, respectively. The steam explosion significantly improved the extraction yield. Similar increase in extraction yields after steam explosion were previously reported (Conde et al., 2009). Further increases in treatment severity led to the decrease of ex-

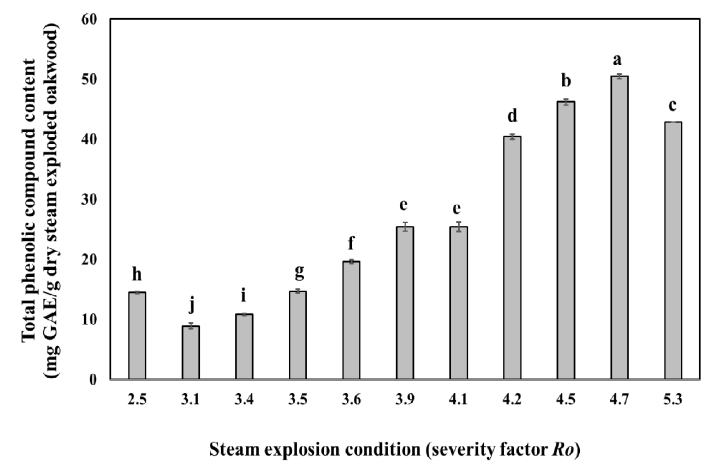

Fig. 2. Effect of steam explosion on total phenolic compound content. The data are expressed as the mean $\pm \mathrm{SD}(n=3)$.

traction yield, probably due to thermal decomposition of phenolic compound and carbohydrate, which coincided with the previous report that the steam explosion could destroy the tight plant texture to enhance the extract yield.

Fig. 2 shows the effect of steam explosion condition on the amount of total phenolic content in oak wood. At a steam temperature of severity factor $R o \quad 3.1$ and severity factor $R o$ 4.7 the amount of total phenolic content increased gradually with the increase of steaming time. The amount of total phenolic content reached their highest equivalent of $50.5 \mathrm{mg}$ GAE/g dry steam exploded oak wood, at a steam temperature of $220^{\circ} \mathrm{C}$ and a steaming time of $15 \mathrm{~min}$ (severity factor Ro 4.7). It seems that the part of lignin was low molecularised and dissolved as low molecular phenolic compounds in water by the hydrolysis reaction with a high temperature and pressure steam followed by the rapid decompression (Cadahía et al., 2001). However, the amount of phenolic compounds decreased at a temperature 
of $240^{\circ} \mathrm{C}$ (severity factor $R 05.3$ ).

Thermal pretreatment with temperatures of $160^{\circ} \mathrm{C}$ and higher, causes, besides the solubilization of hemicellulose, also the solubilization of lignin. The produced compounds are almost always phenolic compounds and have in many cases an inhibitory or toxic effect on bacteria, yeast and methanogens/archae (Gossett et al., 1982). Temperatures of $250^{\circ} \mathrm{C}$ and higher should be avoided during treatment for recovery of phenolic compound, as unwanted pyrolysis reactions start to take place at such temperatures (Brownell et al., 1986).

\subsection{Single Factor Experimental Analysis for RSM}

In the preliminary study, the effects of ethanol concentration, extraction temperature and time on the extraction of total phenolic content were investigated to determine the appropriate experimental ranges for RSM design. To investigate the effect of ethanol concentration on the extraction of total phenolic content, a range from 30 to $90 \%$ of ethanol concentration was used for the investigation.

As shown in Fig. 3(A), the extraction amount of total phenolic content was greatly influenced by the concentration of ethanol. The total phenolic content of the extract initially increased with increasing ethanol concentration until reaching a maximum (73.5 mg GAE/g dry steam exploded wood) at $80 \%$, after which the total phenolic content decreased. The reason might be related to the polarity of ethanol and
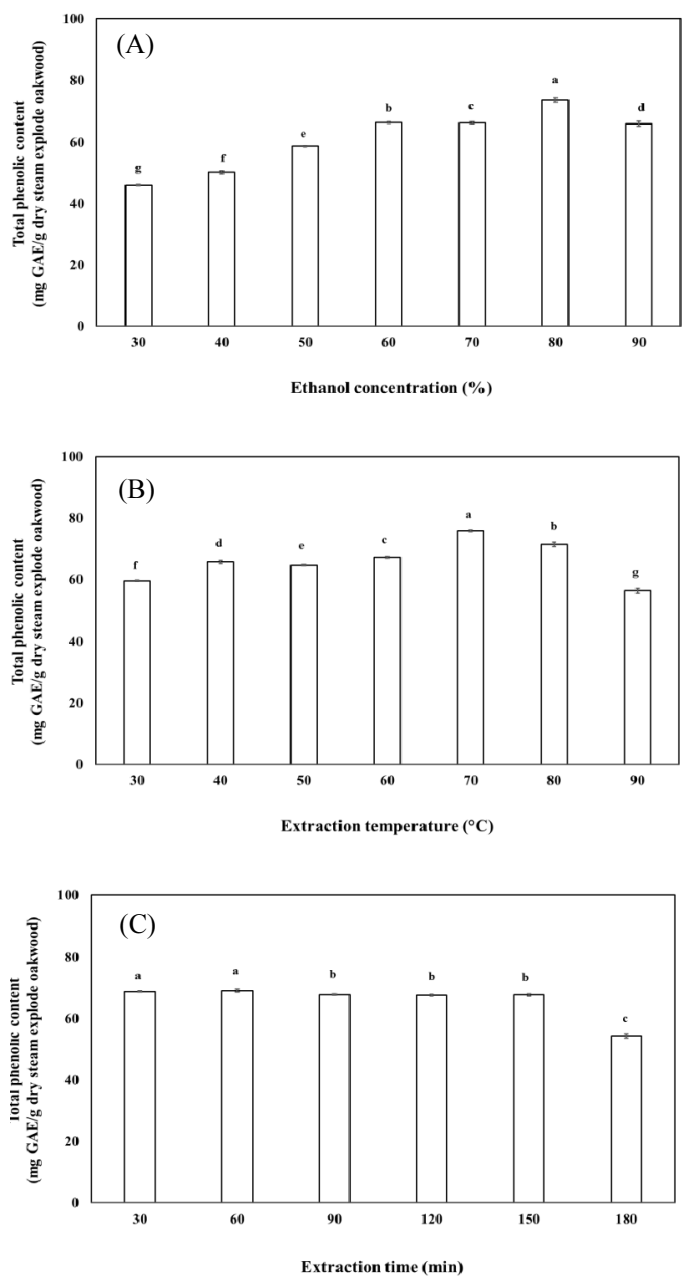

Fig. 3. Effects of ethanol concentration with a 60 min extraction at $60^{\circ} \mathrm{C}$ (A), extraction temperature with an extraction time of $60 \mathrm{~min}$ and ethanol concentration $80 \%$ (B), and extraction time with ethanol concentration $80 \%$ at $70^{\circ} \mathrm{C}(\mathrm{C})$, on the total phenolic content of extracts from steam exploded oak wood (severity value $(R o) 4.71)$. The data are expressed as the mean $\pm \mathrm{SD}(n=3)$.

solubility of polyphenols in steam exploded oak wood. Ethanol was more effective in extracting phenolic compounds from steam exploded oak wood than water, with $80 \%$ ethanol being the 
most efficient extraction solvent.

In the present study, the effect of temperature on the extraction of total phenolic content was investigated. The statistical analysis showed that significant differences existed among the tested temperatures. As shown in Fig. 3(B), the total phenolic content of the extract increased with increasing temperature up to $70^{\circ} \mathrm{C}$, resulting in a maximum total phenolic content $(75.8 \mathrm{mg}$ $\mathrm{GAE} / \mathrm{g}$ dry steam exploded wood) at $70^{\circ} \mathrm{C}$. This finding can be easily explained considering that the increase in temperature positively affect the polyphenol solubility in the extraction of the total phenolic content. The results may be explained by the fact that an increase in extraction temperature may be benefit for antioxidant compound to release from plant component, while temperature higher than optimized level may cause the degradation of some thermo-sensitive compounds.

The effect of extraction time on total phenolic content was investigated as the final step in a series of preliminary experiments. It was found that the total phenolic content in the extract increased with decreasing extraction time from $30 \mathrm{~min}$ to $180 \mathrm{~min}$ (Fig. 3(C)). Over 150 $\mathrm{min}$, the total phenolic content decreased, possibly due to the decomposition of phenolic compounds during the prolonged extraction time.

\subsection{Optimization of Ethanol Extraction from Steam Exploded Oak Wood}

In a preliminary study, ethanol extraction was found to be effective in extracting phenolic compounds from steam exploded oak wood. The ethanol extraction of phenolic compounds from steam exploded oak wood was optimized through the RSM approach. 17 experiments were employed to optimize the parameters, including ethanol concentration, extraction temperature, and extraction time.

The experimental conditions and corresponding responses of the dependent variables (total phenolic content, DPPH radical scavenging activity and antimicrobial activity) are listed in Table 3.

Among the 17 experiments including 5 replicates (Table 3), experiment 14 (ethanol concentration $80 \%$, extraction temperature $70^{\circ} \mathrm{C}$ and extraction time $60 \mathrm{~min}$ ) has the greatest total phenolic content (111.5 mg GAE/g dry steam exploded oak wood) and experiment 16 (ethanol concentration $80 \%$, extraction temperature $80^{\circ} \mathrm{C}$ and extraction time $30 \mathrm{~min}$ ) has the smallest total phenolic content $(94.3 \mathrm{mg}$ GAE$/ \mathrm{g}$ dry steam exploded oak wood). Experiment 2 for DPPH radical scavenging activity (ethanol concentration $80 \%$, extraction temperature $70^{\circ} \mathrm{C}$ and extraction time $60 \mathrm{~min}$ ) has the greatest antioxidant capacity $(66.4 \%$ for DPPH radical scavenging activity). Experiment 11 for DPPH radical scavenging activity (ethanol concentration $90 \%$, extraction temperature $80^{\circ} \mathrm{C}$ and extraction time $60 \mathrm{~min}$ ) has the smallest antioxidant capacity $(51.3 \%$ obtained by DPPH radical scavenging activity methods). Also, experiment 13 (ethanol concentration $80 \%$, extraction temperature $70^{\circ} \mathrm{C}$ and extraction time $60 \mathrm{~min}$ ) has the greatest antimicrobial activity (17.0 
Table 3. Experimental results for the total phenolic content, DPPH free radical scavenging activity and antimicrobial according to the Box-Behnken design

\begin{tabular}{ccccccc}
\hline \multirow{2}{*}{ Run } & $\begin{array}{c}Y_{1}, \text { Total phenolic content }(\mathrm{mg} \mathrm{GAE} / \mathrm{g} \\
\text { dry steam exploded oak wood) }\end{array}$ & \multicolumn{2}{c}{$Y_{2}$, DPPH free radical } & \multicolumn{2}{c}{$Y_{2}$, Antimicrobial activity (mm) } \\
\cline { 2 - 7 } & sctual & Predicted & Actual & Predicted & Actual & Predicted \\
\hline \hline 1 & 100.5 & 101.0 & 59.3 & 57.8 & 12.0 & 12.4 \\
2 & 108.4 & 109.0 & 66.4 & 61.9 & 15.5 & 15.9 \\
3 & 96.3 & 101.1 & 58.8. & 54.9 & 14.5 & 14.6 \\
4 & 107.4 & 103.5 & 57.2 & 56.0 & 13.5 & 13.4 \\
5 & 108.1 & 109.1 & 65.5 & 61.9 & 15.5 & 15.9 \\
6 & 100.2 & 101.1 & 58.0 & 58.3 & 15.5 & 15.0 \\
7 & 105.0 & 100.3 & 59.1 & 59.1 & 14.5 & 14.4 \\
8 & 104.2 & 103.0 & 51.6 & 52.4 & 14.0 & 14.1 \\
9 & 99.3 & 101.0 & 57.9 & 58.9 & 12.0 & 11.6 \\
10 & 98.9 & 95.4 & 53.0 & 51.5 & 15.0 & 14.8 \\
11 & 110.0 & 106.1 & 51.3 & 51.5 & 14.0 & 13.4 \\
12 & 103.1 & 107.1 & 58.5 & 57.7 & 14.0 & 14.5 \\
13 & 110.4 & 109.1 & 58.3 & 61.9 & 17.0 & 15.9 \\
14 & 111.5 & 109.1 & 59.2 & 61.9 & 16.0 & 15.9 \\
15 & 98.8 & 102.8 & 53.8 & 53.2 & 12.5 & 13.1 \\
16 & 94.3 & 97.9 & 53.0 & 54.0 & 14.5 & 14.8 \\
17 & 111.2 & 109.1 & 60.9 & 61.9 & 15.5 & 15.9 \\
\hline
\end{tabular}

$\mathrm{mm})$ and experiment 1 and experiment 9 (ethanol concentration $90 \%$, extraction temperature $70^{\circ} \mathrm{C}$ and extraction time $30 \mathrm{~min}$; ethanol concentration $70 \%$, extraction temperature $70^{\circ} \mathrm{C}$ and extraction time $90 \mathrm{~min}$ ) has the smallest antimicrobial activity $(12.0 \mathrm{~mm})$.

\subsection{Response Surface Analysis of total Phenolic Content}

The experimental data for total phenolic content, DPPH radical scavenging activity and antimicrobial activity were fitted to a response surface quadratic model, and the acquired equation was tested for adequacy of fit to the data. The regression coefficients and the response surface were used to study the impacts of variables on the extraction of total phenolic content, DPPH radical scavenging activity and antimicrobial activity. Regression coefficients of the predicted second - order polynomial models total phenolic content, DPPH radical scavenging activity and antimicrobial activity are shown in Table 4.

The model was adequate and explained most of the variability for extraction of phenolic compound from steam exploded oak wood. For the model fitted, software generates model coefficients, p-values and significant probabilities and hence one can justify the significance of each experimental variable. The maximum pre- 
Table 4. Regression coefficients and of the predicted second order polynomial models for total phenolic content, DPPH free radical scavenging activity and antimicrobial activity

\begin{tabular}{ccccccc}
\hline \multirow{2}{*}{ Model parameter } & \multicolumn{2}{c}{ Total phenolic content } & \multicolumn{2}{c}{ DPPH radical scavenging activity } & \multicolumn{2}{c}{ Antimicrobial activity (mm) } \\
\cline { 2 - 6 } & $\begin{array}{l}\text { Regression } \\
\text { coefficient }\end{array}$ & $P$-value & $\begin{array}{l}\text { Regression } \\
\text { coefficient }\end{array}$ & $P$-value & $\begin{array}{c}\text { Regression } \\
\text { coefficient }\end{array}$ & $P$-value \\
\hline \hline Intercept & -142.407500 & 0.0493 & -427.675000 & 0.0375 & -128.625000 & 0.0069 \\
Linear & & & & & & \\
$X_{1}$ & 2.854650 & 0.0442 & 5.704250 & 0.0124 & 3.070000 & 0.0014 \\
$X_{2}$ & 3.587350 & 0.0305 & 7.862000 & 0.0032 & 0.817500 & 0.1879 \\
$X_{3}$ & 0.197367 & 0.0805 & -0.311417 & 0.0711 & -0.244167 & 0.1084 \\
Quadratic & & & & & & \\
$X_{1}^{2}$ & -0.020490 & 0.0335 & -0.031550 & 0.0127 & -0.019500 & 0.0007 \\
$X_{2}^{2}$ & -0.031990 & 0.0150 & -0.054300 & 0.0022 & -0.004167 & 0.2299 \\
$X_{3}^{2}$ & -0.007471 & 0.0012 & -0.001117 & 0.0593 & -0.000778 & 0.0800 \\
Interaction & & & & & & \\
$X_{1} X_{2}$ & 0.006000 & 0.0776 & -0.009250 & 0.0590 & -0.002500 & 0.4994 \\
$X_{1} X_{3}$ & 0.001250 & 0.0859 & -0.002333 & 0.0771 & 0.004167 & 0.0092 \\
$X_{2} X_{3}$ & 0.008417 & 0.0254 & 0.008750 & 0.0157 & - & 1.0000 \\
\hline
\end{tabular}

dictable response for total phenolic content, DPPH radical scavenging and antimicrobial activity obtained based on a total of 17 experiments required for determining 10 regression coefficients of the model. In general, proceeding with exploration and optimization of a fitted response surface may produce poor or misleading results unless the model exhibits an adequate fit (Myers and Montgomery, 2002).

The relationship between extraction parameters and total phenolic content were investigated by response surface plots. Figs. 4 - 6 shows the effect of ethanol concentration, extraction temperature, extraction time and their mutual interaction on the total phenolic content.

Fig. 4(A) reflects the effects of extraction temperature and extraction time on the ethanol extraction of total phenolic content of steam exploded oak wood. The highest total phenolic content is observed at a higher extraction temperature and higher extraction time. The effect of extraction time and ethanol concentration shown in Fig. 4(B) demonstrated that the total phenolic content increased with the increase of ethanol concentration. The highest total phenolic content was observed with ethanol concentration and extraction time of approximately $80 \%$ and $60 \mathrm{~min}$ respectively. According to the literatures a maximum of phenolic compounds of most plants is extracted with $80 \%$ of ethanol concentration. Similar results have been observed for the ethanol extraction of phenolic compounds from steam exploded oak wood. The highest total phenolic content was observed at a higher extraction temperature (Fig. 4(C)). High temperatures might have increased the diffusion and solubility rate of many compounds resulting in antioxidant compounds being ex- 
(A)

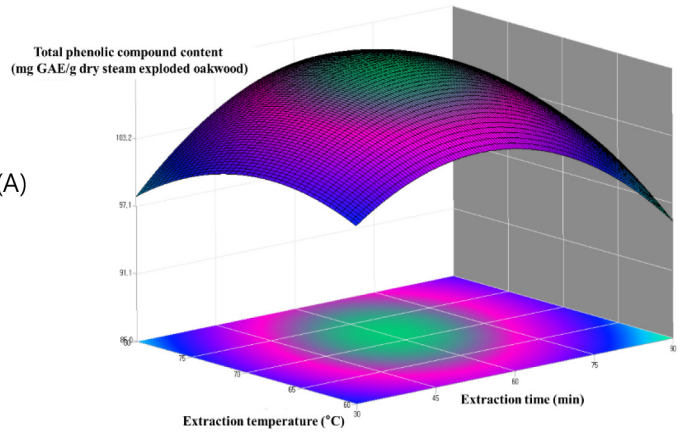

(B)

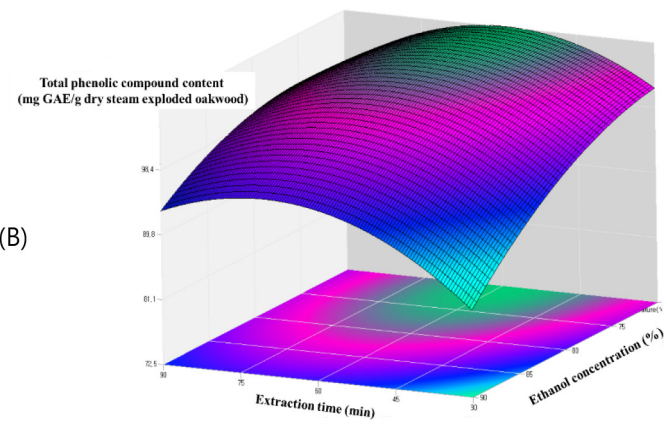

(C)

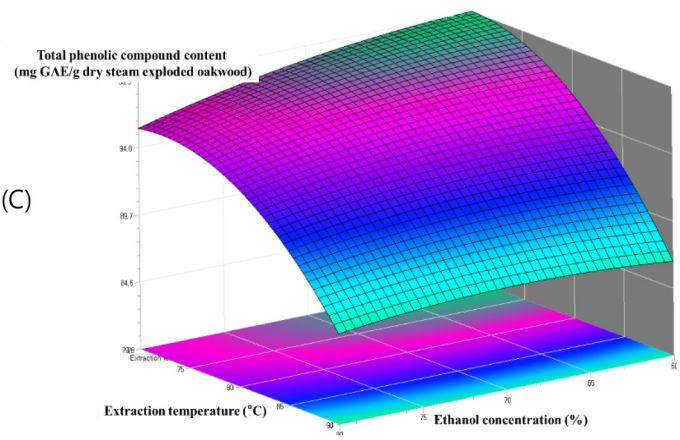

Fig. 4. Response surface plots showing the effects of extraction temperature $\left({ }^{\circ} \mathrm{C}\right)$ and extraction time $(\mathrm{min})$ while kept ethanol concentration at $82.0 \%$ (A), extraction time (min) and ethanol concentration (\%) while kept extraction temperature at $71.7^{\circ} \mathrm{C}$ (B), extraction temperature $\left({ }^{\circ} \mathrm{C}\right)$ and ethanol concentration (\%) while kept extraction time at $60.5 \mathrm{~min}$ (C) on the total phenolic content (mg GAE/g dry steam exploded oak wood) of extracts with ethanol as solvent.
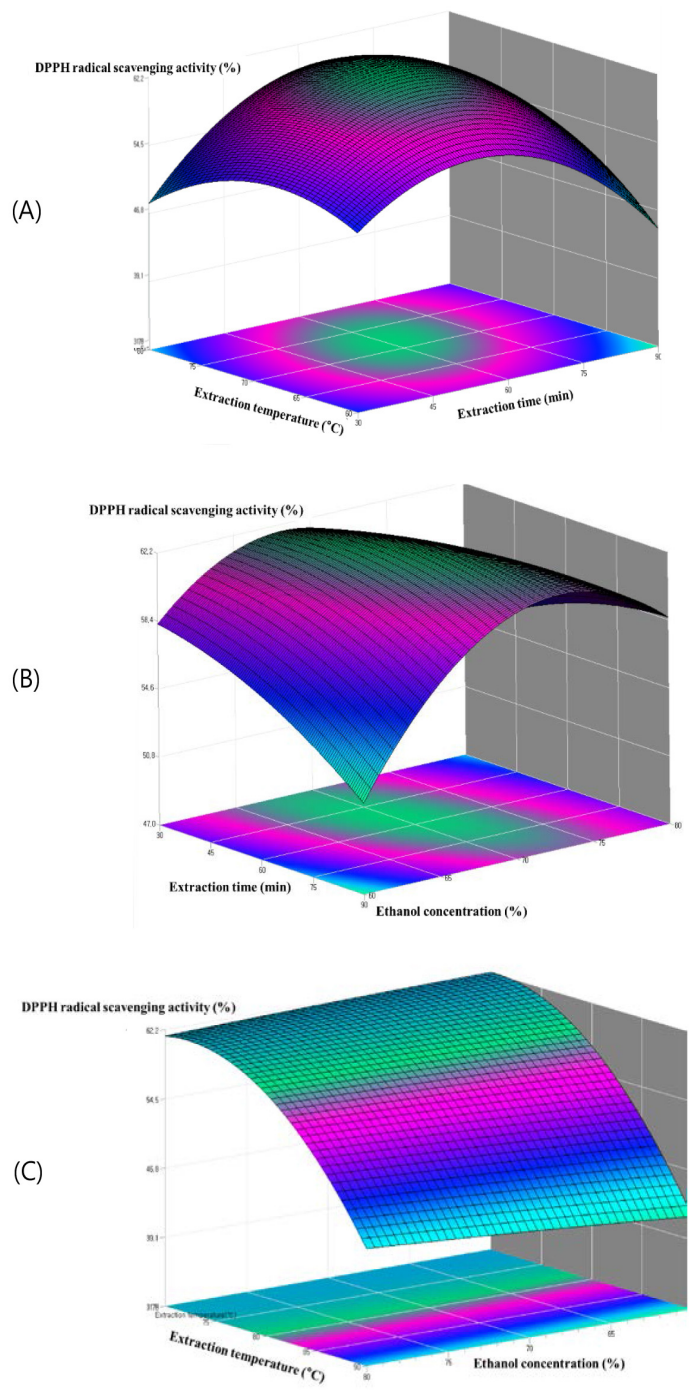

Fig. 5. Response surface plots showing the effects of extraction temperature $\left({ }^{\circ} \mathrm{C}\right)$ and extraction time (min) while kept ethanol concentration at $78.2 \%$ (A), extraction time (min) and ethanol concentration (\%) while kept extraction temperature at $70.0^{\circ} \mathrm{C}$ (B), extraction temperature $\left({ }^{\circ} \mathrm{C}\right)$ and ethanol concentration (\%) while kept extraction time at $53.3 \mathrm{~min}(\mathrm{C})$ on the DPPH radical scavenging activity (\%) of extracts with ethanol as solvent. 
(A)



(B)

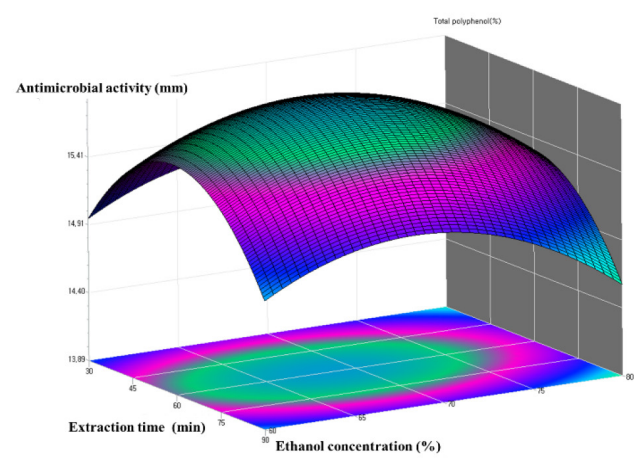

(C)



Fig. 6. Response surface plots showing the effects of extraction temperature $\left({ }^{\circ} \mathrm{C}\right)$ and extraction time (min) while kept ethanol concentration at $80.6 \%$ (A), extraction time (min) and ethanol concentration (\%) while kept extraction temperature at $68.4^{\circ} \mathrm{C}$ (B), extraction temperature $\left({ }^{\circ} \mathrm{C}\right)$ and ethanol concentration (\%) while kept extraction time at $59.0 \mathrm{~min}$ (C) on the antimicrobial activity of extracts with ethanol as solvent. tracted at a higher rate.

The relationships among parameters for every assay can be seen in the contour plots presented in Fig. 5. The contours of the phenolic compounds and the contours of the antioxidant activity were similar resulted. This indicates that the phenolic compound amount is related to the antioxidant activity. As shown in Fig. 5(A), the extraction amount of DPPH radial scavenging activity was greatly influenced by the extraction temperature. The DPPH radial scavenging activity of the extract initially increased with increasing ethanol concentration until reaching a maximum at $78.2 \%$, after which the DPPH radial scavenging activity was decreased. The reason might be related to the polarity of ethanol and the solubility of antioxidant compound in steam exploded oak wood. Fig. 5(B) depicts 3D graphic surface and contour plot of the effects of the two variables, namely, the interaction effect of ethanol concentration (\%) and extraction time on the DPPH radial scavenging activity. The DPPH radial scavenging activity initially increased when there was an increase in the ethanol concentration and extraction time. However, the rounded contour plot and the smooth surface showed that interactions between the variables were insignificant. Fig. 5(C) represents the effects of ethanol concentration (\%) and extraction temperature on the DPPH radial scavenging activity, while the extraction time was fixed. The extraction temperature gave the increase in DPPH radial scavenging activity whereas the ethanol concentration became almost constant at 
Response Surface Optimization of Phenolic Compounds Extraction From Steam Exploded Oak Wood (Quercus mongolica)

Table 5. The fitted quadratic model in terms of coded variables for $Y_{1}, Y_{2}$ and $Y_{3}$ responses

\begin{tabular}{|c|c|c|}
\hline Response & Second order polynomial equation & $R^{2}$ \\
\hline Total phenolic content & $\begin{aligned} Y_{1}= & -142.407500+2.854650 X_{1}+3.587350 X_{2}+0.197367 X_{3} \\
& -0.020490 X_{1}^{2}+0.006000 X_{1} X_{2}-0.031990 X_{2}^{2}+0.001250 X_{1} X_{3} \\
& +0.008417 X_{2} X_{3}-0.007471 X_{3}^{2}\end{aligned}$ & 0.7293 \\
\hline DPPH radical scavenging activity & $\begin{aligned} Y_{2}= & -427.675000+5.704250 X_{1}+7.862000 X_{2}-0.311417 X_{3} \\
& -0.031550 X_{1}^{2}-0.009250 X_{1} X_{2}-0.054300 X_{2}^{2}-0.002333 X_{1} X_{3} \\
& +0.008750 X_{2} X_{3}-0.00117 X_{3}^{2}\end{aligned}$ & 0.7836 \\
\hline Antimicrobial activity & $\begin{aligned} Y_{3}= & -128.625000+3.070000 X_{1}+0.817500 X_{2}-0.244167 X_{3} \\
& -0.019500 X_{1}^{2}-0.002500 X_{1} X 2-0.004500 X_{2}^{2}+0.004167 X_{1} X_{3} \\
& -0.000778 X_{3}^{2}\end{aligned}$ & 0.8885 \\
\hline
\end{tabular}

Table 6. Optimum conditions, predicted and experimental values of responses

\begin{tabular}{|c|c|c|c|c|c|}
\hline \multirow[b]{2}{*}{ Response } & \multicolumn{3}{|c|}{ Optimum ethanol extraction conditions } & \multicolumn{2}{|c|}{ Maximum values } \\
\hline & $\begin{array}{c}\text { Ethanol concentration } \\
(\%)\end{array}$ & $\begin{array}{c}\text { Extraction temperature } \\
\left({ }^{\circ} \mathrm{C}\right)\end{array}$ & $\begin{array}{l}\text { Extraction time } \\
(\min )\end{array}$ & Predicted & Experimental \\
\hline $\begin{array}{l}\text { Total phenolic content } \\
\text { (mg GAE/g dry steam } \\
\text { exploded oak wood }\end{array}$ & 82.0 & 71.7 & 60.5 & 109.2 & $111.8 \pm 1.3$ \\
\hline $\begin{array}{c}\text { DPPH radical } \\
\text { scavenging activity }(\%)\end{array}$ & 78.3 & 70.3 & 57.6 & 62.3 & $65.7 \pm 0.7$ \\
\hline Antimicrobial activity $(\mathrm{mm})$ & 80.6 & 68.4 & 59.0 & 15.9 & $17.0 \pm 0.8$ \\
\hline
\end{tabular}

the following ethanol concentration from $70 \%$ to $90 \%$. Nevertheless, results showed that interactions between the variables were insignificant.

Fig. 6(A) shows the plots at a different extraction time and extraction temperature at fixed ethanol concentration $80.6 \%$. The antimicrobial activity increased within the extraction time from 45 to $75^{\circ} \mathrm{C}$, and the antimicrobial activity increased with the increase of extraction temperature from 60 to 70 . Fig. 6(B) showed the plots at varying extraction time and the ethanol concentration at a fixed extraction temperature $68.4^{\circ} \mathrm{C}$. It can be observed that maximum anti microbial activity could be achieved when the extraction time and the ethanol concentration were $60 \mathrm{~min}$ and 80 , respectively. The plots in
Fig. 6(C), which gives the antimicrobial activity of oak wood as a function of extraction temperature and ethanol concentration at fixed extraction time, indicated that the antimicrobial activity of oak wood increased rapidly with the increasing of the extraction temperature from 60 to $80^{\circ} \mathrm{C}$, and the antimicrobial activity of oak wood was found to increase with the increase of ethanol concentration from 75 to $85 \mathrm{~min}$.

\subsection{Optimization of Extraction Parameters and Validation of the Model}

The optimum ethanol extraction conditions for the total phenolic content, the DPPH radical scavenging activity and antimicrobial activity 
from steam exploded oak wood are given in Table 6. Ethanol concentrations in the range of 78.3 - 82.0\%, extraction temperature of 68.4 $71.7^{\circ} \mathrm{C}$ and extraction time in the range of 57.6 - 60.5 min can result the optimal total phenolic content (109.2 mg GAE/g dry steam exploded oak wood), DPPH radical scavenging activity $(62.3 \%)$ and antimicrobial activity $(15.9 \mathrm{~mm})$ from steam exploded oak wood. The predicted results matched well with experimental results obtained using optimum extraction conditions which validated the response surface methodology model with a good correlation. As a result, the model from Box-Behnken design was considered to be accurate and reliable for predicting the total phenolic compound content and the DPPH radical scavenging activity of steam exploded oak wood for ethanol extraction.

\section{CONCLUSION}

Optimized solvent extraction is proposed here as fast and low cost methodology for the recovery of high-added value phenolic compound in terms of their total phenolic content and DPPH radical scavenging activity from steam exploded oak wood.

The three variables (ethanol concentration, extraction temperature, extraction time) investigated in the present study could be ranked as follows in terms of influence on the extraction performance. Extraction temperature was found to be a significant parameter with major influence on the total phenolic content, antioxidant activity (DPPH radical scavenging) and anti- microbial activity of the extract from stem exploded oak wood. The ethanol to water ratio was also significant for the total phenolic content, antioxidant activity (DPPH radical scavenging) and antimicrobial activity of the extract from stem exploded oak wood. Extraction time was found to be insignificant in this range (30 - $90 \mathrm{~min}$ ).

The conditions for ethanol extraction of steam exploded [severity (Ro) 4.7] oak wood was optimized by using a Box-Behnken design and RSM. The optimal conditions were found to be as follows; (a) total phenolic content: $82.0 \%$ ethanol concentration, $71.7^{\circ} \mathrm{C}, 60.5 \mathrm{~min}$, (b) DPPH radical scavenging activity: $78.3 \%$ ethanol concentration, $70.3{ }^{\circ} \mathrm{C}, 57.6 \mathrm{~min}$, and (c) antimicrobial activity: $80.6 \%$ ethanol concentration, $68.4^{\circ} \mathrm{C}, 59.0 \mathrm{~min}$. Under these conditions, the predicted value of total phenolic content (109.2 mg GAE/g dry steam exploded oak wood), DPPH radical scavenging activity $(62.3 \%)$ and antimicrobial activity $(15.9 \mathrm{~mm})$ was close to the observed values $(111.8 \mathrm{mg}$ GAE/g dry steam exploded oak wood, $65.7 \%$ and $17.0 \mathrm{~mm}$ respectively).

Using steam exploded oak wood as a starting material for the extraction of phenolic compounds via this simple and inexpensive method constitutes a viable use for this forest waste product. The results, by applying fast and low cost technique to obtain added value phenolic compound are of real importance and may have several applications in food and pharmaceutical industry. The contribution of the major constituents of the obtained fractions, to antioxidant 
as well as to other biological activities as a result of synergism are under current investigation.

\section{ACKNOWLEDGEMENTS}

This study was carried out with the support of 'R\&D Program for Forest Science Technology (Project No. 2013070D10-1719-AA03)' provided by Korea Forest Service(Korea Forestry Promotion Institute).

\section{REFERENCES}

Belwal, T., Dhyani, P., Bhatta, I.D., Rawal, R.S., Pande, V. 2016. Optimization extraction conditions for improving phenolic content and antioxidant activity in Berberis asiatica fruits using response surface methodology. Food Chemistry 207: $115 \sim 124$.

Brownell, H.H., Yu, E.K.C. Saddler, J.N. 1986. Steam-explosion pretreatment of wood: effect of chip size, acid, moisture content and pressure drop. Biotechnol Bioeng 28: $792 \sim 801$.

Cacace, J.E. Mazza (2003). Mass transfer process during extraction of phenolic compounds from milled berries. Journal of Food Engineering 59(4): $379 \sim 389$.

Cacace, J.E. Mazza, G. 2002. Extraction of anthocyanins and other phenolics from black currants with sulfured water. Journal of Agricultural Food Chemistry 50(4): 5939 5946.

Cadahía, E., Muñoz, L., Fernández de Simón, B. García-Vallejo, M.C. 2001. Changes in low molecular weight phenolic compounds in spanish, prench, and american oak woods during natural seasoning and toasting. Journal of Agricultural Food Chemistry 49(4): 1790 1798.

Cantos, E., Espin, J., Lopez-Bote, C.C., De La Hoz,
L., Ordonez, J.A., Tomas-Barberan, F.A. 2003. Phenolic compounds and fatty acids from acorns (Quercus spp.), the main dietary constituent of free ranged iberian pigs. Journal of Agricultural Food Chemistry 51: 6248 6255 .

Chatonnet, P., Dubourdie, D., Jean-noël Boidron, Pons, M. 1992. The origin of ethylphenols in wines. Journal of the Science of Food and Agriculture 60(2): 165 178.

Cheung, L.M., Cheung, P.C.K. Ooi, V.E.C. 2003. Antioxidant activity and total phenolics of edible mushroom extracts. Food chemistry 81(2): 249 255.

Conde, E., Cara, C., Moure, A., Ruiz, E., Castro, E, Domínguez, H. 2009. Antioxidant activity of the phenolic compounds released by hydrothermal treatments of olive tree pruning. Food Chemistry 114(3): $806 \sim 812$.

Cutzach, I., Chatonnet, P., Henry, R. Dubourdieu, D. 1997. Identification of Volatile Compounds with a "Toasty" Aroma in Heated Oak Used in Barrelmaking. Journal of Agricultural Food Chemistry 45(6): 2217 2224.

Fu, R., Zhang, Y., Guo, Y., Liu, F. Chen, F. 2014. Determination of phenolic contents and antioxidant activities of extracts of Jatropha curcas L. seed shell, a by-product, a new source of natural antioxidant. Industrial Crops and Products 58: $265 \sim 270$.

Ghasemi, K., Ghasemi, Y. Ebrahimzadeh, M.A. 2009. Antioxidant activity, phenol and flavonoid contents of 13 citrus species peels and tissues. Pakistan Journal of Pharmaceutical Sciences 22(3): $277 \sim 281$.

Gossett, J.M., Stuckey, D.C., Owen, W.F. Mccarty, P.L. 1982. Heat treatment and anaerobic digestion of refuse. Journal of Environmental Engineering Division 108: 437 454.

Heitz M., Carrasco, F., Rubio, M., Brown, A. 
Chornet, E. 1987. Physicochemical characterization of lignocellulosic substrates pretreated via autohydrolysis: an application to tropical woods. Biomass 13: 255 273 .

Li, H.B., Wong, C.C., Cheng, K.W. Chen, F. 2008 Antioxidant properties in vitro and total phenolic contents in methanol extracts from medicinal plants. Lebenson Wiss Technology 41(3): 385 390.

Lopes, I.M.G. Bernardo-Gil, M.G. 2005. Characterization of acorn oils extracted by hexane and by supercritical carbon dioxide. European Journal of Lipid Science and Technology 107: 12 19.

Meullemiestre, A., Petitcolas, E., Maache-Rezzoug, Z., Chemat, F. Rezzoug, S.A. 2016. Impact of ultrasound on solid-liquid extraction of phenolic compounds from maritime pine sawdust waste. Kinetics, optimization and large scale experiments. Ultrason Sonochem 28: 230 239.

Myers, R.H. Montgomery, D.C. 2002. Response surface methodology process and product optimization using designed experiments, John Wiley and Sons, Inc., 2nd ed., New-York, USA.

Panchal, S.K., Brown, L. 2013. Cardioprotective and hepatoprotective effects of ellagitannins from European oak bark (Quercus petraea L.) extract in rats. European Journal of Nutrition 52(1): 397 $\sim 408$.

Pinelo, M., Rubilar, M., Jerez, M., Sineiro, J. Núñez, M.J. 2005. Effect of Solvent, Temperature, and Solvent-to-Solid Ratio on the Total Phenolic Content and Antiradical Activity of Extracts from Different Components of Grape Pomace. Journal of Agricultural and Food Chemistry 53(6): $2111 \sim 2117$.

Sa'adi, R.A., Kamaludin, N.H.I., Zakaria, Z., Arbain, D., MohdIdris, Z., Abdullah, N.A.H. 2014. Evaluation of Phenolic Compound Extraction from LimauKasturi (Citrus macrocarpa) Peels Extract. Advances in Environmental Biology 8(22): $73 \sim 76$.

Salem, M.Z.M., Abdel-Megeed, A., Ali, H.M. 2014. Stem Wood and Bark Extracts of Delonix regia (Boj. Ex. Hook): Chemical Analysis and Antibacterial, Antifungal, and Antioxidant Properties. BioResources 9(2): 2382 2395.

Sanz, M., Cadahía, E., Esteruelas, E., Muńoz, Á.M., Fernández De Simón, B., Hernández, T., Estrella, I. (2010). Phenolic Compounds in Chestnut (Castanea sativa Mill.) Heartwood. Effect of Toasting at Cooperage. Journal of Agricultural and Food Chemistry 58: 9631 9640.

Sarni, F., Moutounet, M., Puech., J.L. Rabier, P. 1990. Effect of heat treatmant of oak wood extractable compounds. Holzforschung 44: 461 466.

Sasidharan, S., Chen, Y., Saravanan, D., Sundram, K.M., Latha, L.Y. 2011. Extraction, Isolation And Characterization of Bioactive Compounds From Plants' Extracts. African Journal of Traditional, Complementary and Alternatives medicines 8(1): $1 \sim 10$.

Sim, J.S. Han, S.S. 2003. Ecophysiological characteristics of deciduous oak species (III) Photosynthetic responses of leaves to change of light intensity. Journal of Korean Forestry Society 93: $208 \sim 204$.

Spigno, G. De Faveri, D.M. 2007. Antioxidants from grape stalks and marc: Influence of extraction procedure on yield, purity and antioxidant power of the extracts. Journal of Food Engineering 78(3): $793 \sim 801$.

Wang, W., Guo, J., Zhang, J., Peng, J., Liu, T. Xin, Z. 2015. Isolation, identification and antioxidant activity of bound phenolic compounds present in rice bran. Food Chemistry 171: 40 49 . 
Response Surface Optimization of Phenolic Compounds Extraction From Steam Exploded Oak Wood (Quercus mongolica)

Wettasinghe, M., Shahidi, F. 1999. Antioxidant and free radical-scavenging properties of ethanolic extracts of defatted borage (Borago officinalis L.) seeds. Food Chemistry 67(4): 399 414.

Wong, W.H., Lee, W.X., Ramanan, R.N., Tee, L.H., Kong, K.W., Galanakis, C.M., Sun, J., Prasad, K.N. 2015. Two level half factorial design for the extraction of phenolics, flavonoids and antioxidants recovery from palm kernel by-product. Industrial Crops and Products 63: 238 248.
Yilmaz, Y. Toledo, R.T. 2006. Oxygen radical absorbance capacities of grape/wine industry byproducts and effect of solvent type on extraction of grape seed polyphenols. Journal of Food Composition Analysis 19(1): 41 48.

Zhao, H.X., Zhang, H.S. Yang, S.F. 2014. Phenolic compounds and its antioxidant activities in ethanolic extracts from seven cultivars of Chinese jujube. Food Science and Technology-Leb 3(3-4): 183 190. 